\title{
Transplante renal, infecções associadase suas medidas terapêuticas: uma revisão de literatura
}

Kidney transplantation, associated infections and their therapeutic measures: a literature review

Trasplante renal, infecciones asociadas y sus medidas terapéuticas: una revisión de la literatura

Phelipe Von Der Heide Sarmento ${ }^{1 *}$, Aline de Jesus Oliveira ${ }^{1}$, Ana Paula de Oliveira Miranda ${ }^{1}$, Carla Resende Vaz Oliveira ${ }^{1}$, Maria Thereza Castilho dos Santos ${ }^{1}$, Marianna da Cunha Corrêa ${ }^{1}$, Thales Montela Marins ${ }^{1}$, Bruno Cezario Costa Reis ${ }^{1}$.

\section{RESUMO}

Objetivo: Analisar o padrão de infecções relacionadas a receptores de transplante renal, relacionando com possíveis métodos terapêuticos. Avaliando, assim, a relevância do manejo dos quadros infecciosos. Métodos: A abordagem metodológica deste trabalho se propõe a um compilado de pesquisa bibliog ráfica de abordagem qualitativa e caráter descritivo por meio de uma revisão integrativa da literatura nas bases de dados utilizadas foram o National Library of Medicine, Biblioteca Virtual em Saúde e Directory of Open Access Journals. Os descritores utilizaram foram: "kidney transplantation", "infections" e "therapeutic". Os critérios de inclusão foram os artigos originais, ensaios clínicos, randomizados ou não randomizados, estudos de caso -controle e estudos de coorte, artigos de livre acesso, artigos em inglês, português, espanhol, entre 2017 a 2022. Resultados: As complicações infeciosas, infecções sintomáticas do trato urinário de forma geral e inf ecções por patógenos específicos como o vírus da hepatite A, vírus Epstein-Barr, poliomavírus BK, citomegalovírus, vírus SARS-CoV-2, vírus da hepatite $\mathrm{C}$, vírus linfotrópico T humano tipo 1 e Simkania negevensis, podem acometer pacientes receptores de transplante renal. Considerações finais: Dessa forma, foi observado que como reflexo da terapia imunossupressora e outros fatores, tais receptores estão vulneráveis a desenvolverem variados quadros infecciosos, possuindo diferentes agentes etiológicos, desfechos e medidas terapêuticas.

Palavras-chave: Transplante renal, Infecções, Medidas terapêuticas.

\begin{abstract}
Objective: To analyze the pattern of infections related to renal transplant recipients, relating them to possible therapeutic methods. Evaluating, thus, the relevance of the management of infectious conditions. Methods: The methodological approach of this work proposes a compilation of biblio graphic research with a qualitative approach and descriptive character through an integrative literature review in the databases used were the National Library of Medicine, Virtual Health Library and Directory of Open Access Journals. The descriptors used were: "kidney transplantation", "infections" and "therapeutic". Inclusion criteria were original articles, clinical trials, randomized or non-randomized, case-control studies and cohort studies, open access articles, articles in English, Portuguese, Spanish, between 2017 and 2022. Results: Infectious complications, symptomatic urinary tract infections in general and infections by specific pathogens such as the hepatitis $A$ virus, Epstein-Barr virus, BK polyomavirus, cytomegalovirus, SARS-CoV-2 virus, hepatitis C virus, T lymphotropic virus human type 1 and Simkania negevensis, can affect kidney transplant recipients. Final considerations: Thus, it was observed that as a reflection of immunosuppressive therapy and other factors,
\end{abstract}

1 Universidade de Vassouras, Vassouras - RJ. `E-mail: phelipevonderheide2009@hotmail.com

SUBMETIDO EM: 2/2022

ACEITO EM: 2/2022

PUBLICADO EM: 2/2022 
such receptors are vulnerable to developing different infectious conditions, having different etiological agents, outcomes and therapeutic measures.

Keywords: Renal transplantation, Infections, Therapeutic measures.

\section{RESUMEN}

Objetivo: Analizar el patrón de infecciones relacionadas con los receptores de trasplante renal, relacionándolos con posibles métodos terapéuticos. Evaluando, así, la relevancia del manejo de las condiciones infecciosas. Métodos: El enfoque metodológico de este trabajo propone una recopilación de investigaciones bibliog ráficas con enfoque cualitativo y carácter descriptivo a través de una revisión integrativa de la literatura en las bases de datos utilizadas fueron Biblioteca Nacional de Medicina, Biblioteca Virtual en Salud y Directorio de Revistas. Acceso abierto. Los descriptores utilizados fueron: "trasplante renal", "infecciones" y "terapéutico". Los criterios de inclusión fueron artículos originales, ensayos clínicos, aleatorizados o no aleatorizados, estudios de casos y controles y estudios de cohortes, artículos de acceso abierto, artículos en inglés, portugués, español, entre 2017 y 2022. Resultados: Complicaciones infecciosas, infecciones urinarias sintomáticas generales y infecciones patogénicas específicas, como el virus de la hepatitis A, virus de Epstein-Barr, poliomavirus BK, citomegalovirus, virus SARS-CoV-2, virus de la hepatitis $C$, virus linfotrópico T humano tipo 1 y Simkania negevensis pueden af ectar a los receptores del trasplante renal. Consideraciones finales: Así, se observó que, como reflejo de la terapia inmunosupresora y otros factores, estos receptores son vulnerables a desarrollar diferentes condiciones infecciosas, teniendo diferentes agentes etiológicos, desenlaces y medidas terapéuticas.

Palabras clave: Trasplantación renal, Infecciones, Procedimientos terapéuticos.

\section{INTRODUÇÃO}

O transplante de órgãos é um grande avanço na medicina moderna e representa uma possibilidade para que pacientes com falência de determinados órgãos tenham uma melhoria em sua qualidade de vida e sobrevida. Como reflexo dos avanços técnico-científicos em diversas áreas do conhecimento possibilitou-se que os seres humanos obtivessem uma melhor qualidade de vida e consequentemente passassem a ter um aumento em sua longevidade. Contudo, atrelado ao envelhecimento da população ocorre o aumento de morbidades e da incidência de doenças crônicas, dentre elas a Doença Renal Crônica (DRC) (TIZO JM e MACEDO LC, 2015; GARCIA GG, et al., 2012).

A DRC cursa com uma queda progressiva da taxa de filtração glomerular, o que gerará reverberações sistêmicas para o indivíduo acometido. Ao curso da história natural da doença o indivíduo atingirá um estágio terminal com um quadro de Insuficiência Renal Irreversível, necessitando de Terapia Renal Substitutiva(TRS) sendo ela por meio de: dialise, hemodiálise e transplante renal. Sendo o transplante renal é a melhor opção de tratamento para a DCR, tendo em vista os seus resultados em sobrevida e o seu custo (TIZO JM e MACEDO LC, 2015).

No ano de 2015 foram realizados 5.648 transplantes renais no Brasil, configurando-se como o segundo que mais realiza esse procedimento cirúrgico. Contudo, ao ser avaliado o número de transplantes renais por mil habitantes o país fica em trigésimo terceiro lugar. Dessa forma, mesmo o país apresentando um número total de transplantes renais bastante expressivo ele é insuficiente para atender a demanda existente (PIOVESAN A e NAHAS WC, 2018).

O Brasil apresenta um grande potencial de crescimento nos números de transplantes renais, tendo em vista que apenas cerca de $30 \%$ de indivíduos potenciais doadores realmente se tornam doadores. Uma das causas dessa não ef etivação é a recusa familiar, a qual está atrelada a desconhecimento relacionado aos protocolos de morte encefálica, a aspectos religiosos, culturais e sociais (PIOVESAN A e NAHAS WC, 2018; GARCIA GG, et al., 2012). 
Os transplantes sof rem interferência do grau de histocompatibilidade entre o doadore o receptor. Uma vez que ao ser transplantado um órgão haverá uma resposta imune, onde as células de defesa do organismo reconhecerão as células do órgão transplantado e mediante ao grau de similaridade entre os tecidos poderá haver ou não rejeição imunológica. A rejeição do órgão poderá ser hiperaguda que ocorre de minutos ou horas após o transplante, aguda ocorrendo após uma semana e crônica que pode ocorrer de duas semanas há anos (BARBOSA JT, et al., 2020; TIZO JM e MACEDO LC, 2015).

Objetivando-se a manutenção da viabilidade do transplante mediante necessidade podem ser prescritos aos receptores do transplante terapias imunossupressoras. Os esquemas de imunossupressão são formados principalmente por quatro classe de fármacos: glicocorticoides, inibidores da calcineurina (ciclosporina, tacrolimo), fármacos antiproliferativos e antimetabólicos (azatioprina, micofenolato de mofetil) e anticorpos (policlonais, monoclonais murinos e monoclonais quiméricos e humanizados). Desta forma, é fund amental o acompanhamento ambulatorial dos receptores que fazem uso desse tipo de terapia para assegurar o sucesso a longo prazo do transplante e o manejo das complicações associadas a esse tipo de terapia (BARBOSA JT, et al., 2020; TIZO JM e MACEDO LC, 2015).

A terapia imunossupressora apresenta várias complicações como: metabólicas (dislipidemia, obesidade, diabetes mellitus), cardiovasculares (hipertensão arterial), disfunção óssea, nefrotoxicidade, proteinúria, anemia, infecciosas e imunológicas, dentre outras. Destarte, o manejo da terapia imunossupressora deve sempre almejar o bem-estar do paciente e considerar os riscos e benefícios (TIZO JM e MACEDO LC, 2015).

A terapia imunossupressora interfere na resposta imunológica do organismo e abre precedentes para que ocorram infecções bacterianas, fúngicas e virais. Essa lacuna aberta pela terapia imunossupressora apresenta grande influência na alta incidência de morbimortalidade devido a complicações infeciosas em recém transplantados (STARCK É, et al., 2020).

De tal maneira, esta revisão teve como objetivo analisar o padrão de infecções relacionadas a pacientes receptores de transplante renal, relacionando com possíveis métodos terapêuticos. Avaliando, assim, a relevância do manejo dos quadros infecciosos nesses pacientes transplantados.

\section{MÉTODOS}

A abordagem metodológica do presente trabalho se baseia em um compilado de pesquisa bibliográfica de abordagem qualitativa e caráter descritivo por meio de uma revisão integrativa da literatura. As bases de dados utilizadas foram o National Library of Medicine (PubMed), Biblioteca Virtual em Saúde (BVS) e Directory of Open Access Journals (DOAJ).

A busca pelos artigos foi realizada por meio dos descritores: "kidney transplantation", "infections" e "therapeutic" utilizando o operador booleano "and". Os descritores citados foram usados apenas na língua inglesa e são encontrados nos Descritores de Ciências da Saúde (DeCS).

A revisão de literatura foi realizada seguindo as seguintes etapas: estabelecimento do tema; definição dos parâmetros de elegibilidade; def inição dos critérios de inclusão e exclusão; verificação das publicações nas bases de dados; exame das informações encontradas; análise dos estudos encontrados e exposição dos resultados. Seguindo essa sistemática, após a pesquisa dos descritores nos sites, foram estabelecidos critérios de inclusão e exclusão.

Ocorreu a utilização de filtros de pesquisa como newspaper article e clinical trial. Também foram usados os seguintes filtros: artigos de livre acesso, artigos publicados em inglês, português, espanhol. Foram incluídos todos os artigos originais, ensaios clínicos, randomizados ou não randomizados, estudos de caso controle e estudos de coorte. Além disso, foi critério de inclusão o recorte temporal de publicação de 2017 a 2022 .

Os critérios de exclusão são artigos de revisão de literatura, resumos e meta-análise. Os artigos excluídos não estavam dentro do contexto abordado, fugindo do objetivo da temática sobre as infecções relacionadas à pacientes submetidos a transplante renal e as medidas terapêutic as para esses quadros infecciosos. 


\section{RESULTADOS}

Após a associação de todos os descritores nas bases pesquisadas foram encontrados 22.814 artigos. Foram encontrados 22.777 artigos na base de dados PubMed, 34 artigos na BVS e três artigos na DOAJ. Após a aplicação dos critérios de inclusão e exclusão foram selecionados 24 artigos na base de dados PubMed e um artigo na BVS, totalizando para análise completa 25 artigos, conforme apresentado na Figura 1.

Figura 1 - Fluxograma de identificação e seleção dos artigos selecionados nas bases de dados PubMed, Biblioteca Virtual em Saúde e DOAJ.

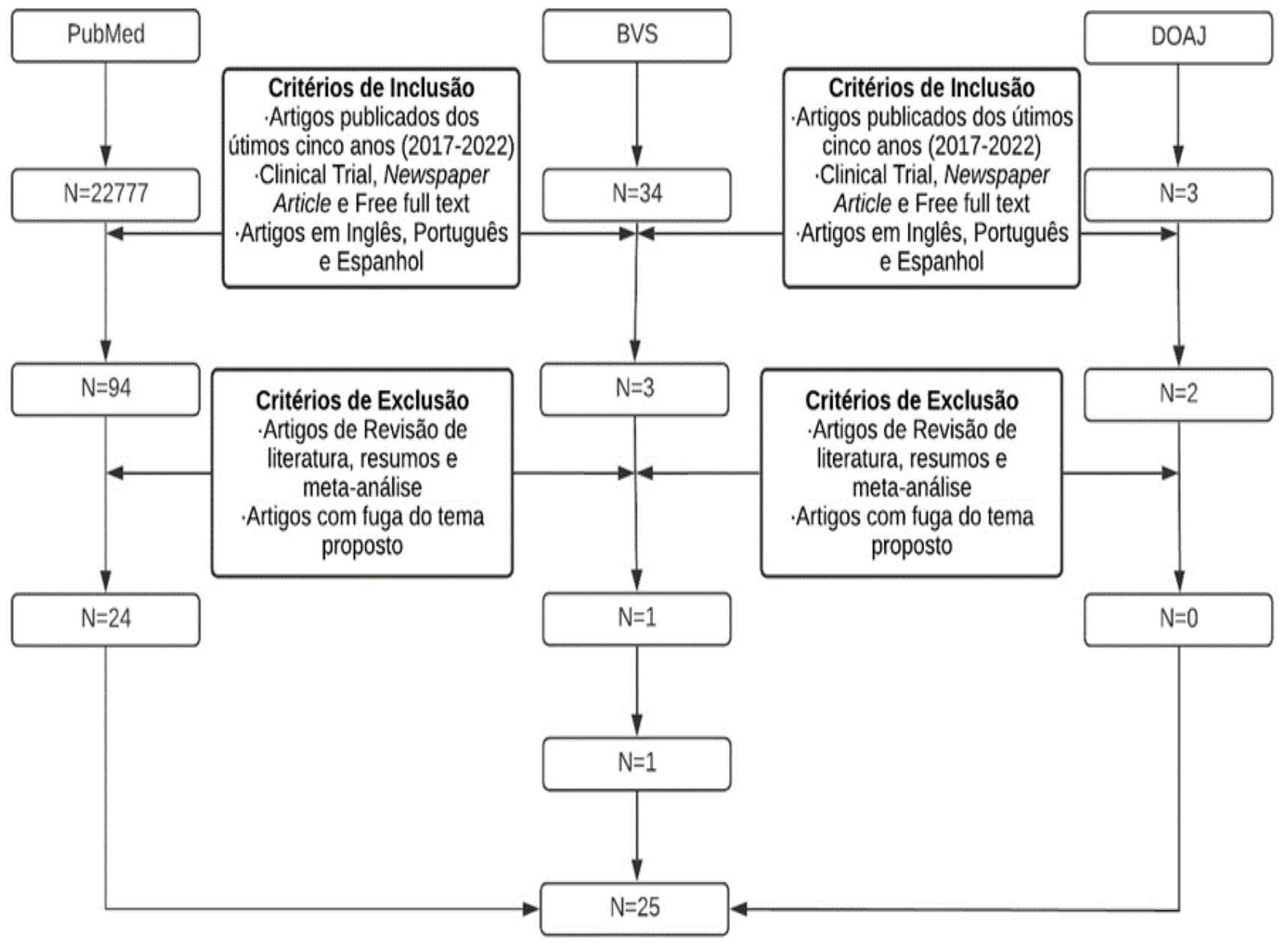

Fonte: Sarmento PVDH, et al., 2022.

Os 25 artigos selecionados abordam as complicações infeciosas e infecções sintomáticas do trato urinário de forma geral associadas a pacientes receptores de transplante renal, ademais também foram relacionados no presente estudo infecções causadas por patógenos específicos tais quais: vírus da hepatite A, vírus Epstein-Barr, poliomavírus BK, citomegalovírus, coronavirus 2 da síndrome respiratória aguda grave (SARSCoV-2), vírus da hepatite $C$, vírus linfotrópico Thumano tipo 1 e Simkania negevensis.

Além disso, os artigos em sua maioria também discorrem sobre medidas terapêuticas associadas a esses quadros infecciosos e apresentam os resultados obtidos pelas pesquisas realizadas. Foram avaliados os resultados dos trabalhos selecionados e construindo um quadro comparativo, no qual é composto pelo número de indivíduos abordados nos estudos, ano de publicação, quadros infecciosos, medidas terapêuticas e principais achados conforme no Quadro 1. 
Quadro 1 - Caracterização dos artigos conforme ano de publicação, número de indivíduos abordados, infecções relacionadas a receptores de transplante renal, medidas terapêuticas e principais achados.

\begin{tabular}{|c|c|c|c|c|}
\hline Autores (Ano) & $\mathbf{N}$ & Infecções & Medidas Terapêuticas & Principais achados \\
\hline COUSSEMENT J, et al. (2021). & 199 & $\begin{array}{c}\text { Bacteriúria } \\
\text { assintomática }\end{array}$ & Antibioticoterapia ou nenhuma terapia. & $\begin{array}{l}\text { Antibioticoterapia não reduziu a ocorrência de ITU } \\
\text { sintomática. }\end{array}$ \\
\hline $\begin{array}{l}\text { PRASOPPOKAKORN T, et al. } \\
\text { (2021). }\end{array}$ & 401 & HAV & Vacina contra HAV regimes de duas e três doses. & $\begin{array}{l}\text { Regime de três doses não demonstrou benefício } \\
\text { superior. }\end{array}$ \\
\hline THUKRAL S, et al. (2021). & 52 & $\begin{array}{c}\text { Complicações } \\
\text { infeciosas }\end{array}$ & Ajuste da dose de RTX & $\begin{array}{l}\text { RTX de baixa dose resulta em uma taxa } \\
\text { significativamente menor de infecções graves. }\end{array}$ \\
\hline BAJDA S, et al. (2020). & 540 & EBV & $\begin{array}{l}\text { Análise da concentração dos seguintes fatores } \\
\text { solúveis: IL-4, IL-5, IL-6, IL-10, IL-21, TNFa, APRIL e } \\
\text { BAFF. }\end{array}$ & $\begin{array}{l}\text { A reativação da doença foi simultaneamente } \\
\text { associada ao aumento dos níveis de BAFF. }\end{array}$ \\
\hline JEHN U, et al. (2020). & 723 & BKV e CMV & Biopsia renal. & Rejeição aguda com função inferior do enxerto. \\
\hline MERINO JC de la F, et al. (2020). & 1 & $\begin{array}{l}\text { Vírus SARS- } \\
\text { CoV-2 }\end{array}$ & $\begin{array}{l}\text { Hidroxicloroquina, lopinavir/ritonavir, azitromicina, } \\
\text { ceftriaxona, tocilizumabe, metilprednisolona e IGIV. }\end{array}$ & Terapia imunossupressora deve ser individualizada. \\
\hline $\begin{array}{l}\text { ROSADO-CANTO R, et al. } \\
(2020) \text {. }\end{array}$ & 82 & ITUs & $\begin{array}{l}\text { Profilaxia com Trimetropim }+ \text { Sulfametoxazol e } \\
\text { Fosfomicina. }\end{array}$ & $\begin{array}{l}\text { A adição de fosfomicina reduziu a ocorrência de } \\
\text { ITUs. }\end{array}$ \\
\hline BASIC-JUKIC N, et al. (2019). & 117 & CMV & $\begin{array}{l}\text { Profilaxia com valganciclovir em } \text { diferentes } \\
\text { formulações. }\end{array}$ & $\begin{array}{l}\text { Formulações genéricas nãos são inferiores quanto à } \\
\text { segurança e eficácia. }\end{array}$ \\
\hline COUSSEMENT J, et al. (2019). & 579 & $\begin{array}{c}\text { Bacteriúria } \\
\text { assintomática }\end{array}$ & - & $\begin{array}{l}\text { Prevalência de } 3,4 \% \text { entre os receptores de } \\
\text { transplante renal além do segundo mês pós- } \\
\text { transplante. }\end{array}$ \\
\hline HALIM MA, et al. (2019). & 201 & CMV & Profilaxia com valganciclovir em baixa dose. & $\begin{array}{l}\text { A profilaxia reduziu a incidência de infecções por } \\
\text { CMV até } 2 \text { anos após o transplante. }\end{array}$ \\
\hline $\begin{array}{l}\text { HEMMERSBACH-MILLER M, et } \\
\text { al. (2019). }\end{array}$ & 551 & $\begin{array}{l}\text { Complicações } \\
\text { infeciosas }\end{array}$ & - & $\begin{array}{l}\text { Receptores mais velhos têm uma incidência muito } \\
\text { alta de ITUs e reativações de CMV. }\end{array}$ \\
\hline PATEL SJ, et al. (2019). & 200 & BKV & Profilaxia com Ciprofloxacina. & $\begin{array}{l}\text { Ineficaz para prevenção da viremia e foi associado } \\
\text { ao aumento de infecções resistentes a } \\
\text { fluoquinolonas. }\end{array}$ \\
\hline STRANAVOVA L, et al. (2019). & 78 & CMV & $\begin{array}{l}\text { Rastreamento de células } T \text { funcionais de reatividade } \\
\text { cruzada e seus clonótipos. }\end{array}$ & $\begin{array}{l}\text { Presença de células T específicas para CMV prediz } \\
\text { rejeição de transplante renal e pior função do } \\
\text { enxerto em } 1 \text { ano. }\end{array}$ \\
\hline ZHANG J, et al. (2019). & 26 & $\mathrm{HCV}$ & $\begin{array}{l}\text { AAAD. Monoterapia SOF. Terapia combinada SOF + } \\
\text { LDV ou DCV. }\end{array}$ & $\begin{array}{l}\text { O tratamento antiviral é persistentemente eficaz e } \\
\text { bem tolerado. }\end{array}$ \\
\hline $\begin{array}{l}\text { BLAZQUEZ-NAVARRO A, et al. } \\
\text { (2018). }\end{array}$ & 615 & $\begin{array}{l}\text { Reativações } \\
\text { BKV, CMV e } \\
\text { EBV }\end{array}$ & Monitorização da carga viral de BKV, CMV e EBV. & $\begin{array}{l}\text { BKV - complicação viral mais relevante. BKV-CMV } \\
\text { tem um impacto profundo na função renal um ano } \\
\text { após o transplante. }\end{array}$ \\
\hline
\end{tabular}




\begin{tabular}{|c|c|c|c|c|}
\hline Autores (Ano) & $\mathbf{N}$ & Infecções & Medidas Terapêuticas & Principais achados \\
\hline DENG R, et al. (2018). & 120 & CMV & Prevenção da infecção e doença utilizando RG7667. & $\begin{array}{l}\text { Exposições de anticorpos RG7667 ou componentes } \\
\text { maiores que os respectivos valores medianos } \\
\text { tiveram uma incidência menor de viremia em } 12 \\
\text { semanas e } 24 \text { semanas após o transplante e um } \\
\text { tempo mais longo para viremia detectável por CMV. }\end{array}$ \\
\hline KAWANO N, et al. (2018). & 85 & HTLV-1 & $\begin{array}{l}\text { Teste para HTLV-1 e farmacoterapia } \\
\text { imunossupressora. }\end{array}$ & $\begin{array}{l}\text { Acompanhamento cuidadoso de receptores } \\
\text { infectados por HTLV-1 após transplante divido ao } \\
\text { risco de desenvolvimento de ATL ou HAM. }\end{array}$ \\
\hline REAU N, et al. (2018). & 100100 & $\begin{array}{l}\text { HCV - } \\
\text { Infecção } \\
\text { crônica }\end{array}$ & Tratamento com Glecaprevir/Pibrentasvir. & Tratamento bem tolerado e eficaz. \\
\hline REISCHIG T, et al. (2018). & 127 & CMV & Profilaxia de valganciclovir e valaciclovir para CMV. & $\begin{array}{l}\text { Profilaxia foi associada a um risco reduzido de } \\
\text { fibrose intersticial moderada a grave e atrofia } \\
\text { tubular. }\end{array}$ \\
\hline WAGENLEHNER F, et al. (2018). & 225 & $\begin{array}{c}\text { ITUs } \\
\text { complicadas e } \\
\text { pielonef rite }\end{array}$ & Tratamento com Finafloxacina versus Ciprofloxacina. & $\begin{array}{l}\text { Finafloxacina resultou em alta erradicação e } \\
\text { melhores taxas de resultados clínicos. }\end{array}$ \\
\hline ANGELETTI A, et al. (2017). & 315 & $\begin{array}{c}\text { Simkania } \\
\text { negevensis }\end{array}$ & Avaliação de $\lg G$ e $\lg A$ para Simkania negevensis. & $\begin{array}{l}\text { Detectou-se pela primeira vez a ocorrência de S. } \\
\text { negevensis em pacientes em hemodiálise e } \\
\text { transplante renal. }\end{array}$ \\
\hline BONANI M, et al. (2017). & 90 & $\begin{array}{c}\text { Complicações } \\
\text { infeciosas }\end{array}$ & Denosumab. & $\begin{array}{l}\text { Tratamento no primeiro ano foi associado a } \\
\text { episódios de infecções do trato urinário. }\end{array}$ \\
\hline GHEITH O, et al. (2017). & 201 & CMV & Profilaxia com valganciclovir em baixas doses. & $\begin{array}{l}\text { A profilaxia é mais segura, eficaz e sem inf ecção, e } \\
\text { menos oneroso do que usar a dose usual. }\end{array}$ \\
\hline ISHIDA JH, et al. (2017). & 138 & CMV & Prevenção da infecção e doença utilizando RG7667. & $\begin{array}{l}\text { RG7667 foi bem tolerado, reduziu a incidência de } \\
\text { infecção por CMV, atrasou o tempo de viremia por } \\
\text { CMV e foi associado a menos doença. }\end{array}$ \\
\hline PATEL P, et al. (2017). & 459 & ITUs & $\begin{array}{l}\text { Colocação de stent ureteral profilático. Remoção } \\
\text { precoce versus tardia. }\end{array}$ & $\begin{array}{l}\text { Remoção precoce reduziu significativamente as } \\
\text { complicações do stent - principalmente, ITUs - nos } \\
\text { primeiros } 3 \text { meses após o transplante. }\end{array}$ \\
\hline
\end{tabular}

Legenda: HAV = Vírus da hepatite A; RTX = rituximab; EBV = Reativação do vírus Epstein-Barr; BAAF = Fator de ativação de células B; BKV = Poliomavírus BK; CMV = citomegalovírus; ITUs = Infecção sintomática do trato urinário; HCV = Vírus da hepatite C; AAAD = Agentes antivirais de ação direta; SOF = Sofosbuvir; LDV = Ledipasvir; DCV = Daclatasvir; HTLV-1 = Vírus linfotrópico Thumano tipo 1; ATL = leucemia-linfoma de células T do adulto; HAM = mielopatia associada ao HTLV-1.

Fonte: Sarmento PVDH, et al., 2022. 
Dos vinte e cinco artigos selecionados, oito (32\%) abordam de forma ampla os quadros infecciosos associados com receptores de transplante renal, sendo dois $(8 \%)$ sobre bacteriúria assintomática, três (12\%) sobre complicações infecciosas, dois (8\%) sobre inf ecções sintomáticas do trato urinário (ITUs) e um (4\%) sobre ITUs e pielonefrite.

Os outros dezessete artigos (68\%) avaliaram infecções especificas que acometem esses pacientes transplantados. Sendo os agentes infecciosos estudados: vírus da hepatite A, vírus Epstein-Barr, poliomavírus BK, citomegalovírus, vírus SARS-CoV-2, vírus da hepatite C, vírus linfotrópico T humano tipo 1 e Simkania negevensis.

A infecção pelo citomegalovírus foi abordada em nove (36\%) dos artigos avaliados, sendo que em cada um deles foram estudados pontos diferentes quanto as medidas terapêuticas que devem ser adotadas nos receptores. Vale pontuar que as medidas terapêuticas incluem procedimentos de diagnóstico, de segmento, de prognóstico e de profilaxia.

A infecção pelo vírus da hepatite foi avaliada em três (12\%) artigos, sendo um (4\%) sobre a infecção causada pelo vírus da hepatite A e dois (8\%) pelo vírus da hepatite C. Quanto aos outros quadros infecciosos foram avaliados: três (12\%) artigos sobre o Poliomavírus BK, um (4\%) artigo sobre o vírus SARS-CoV-2, dois (8\%) sobre vírus Epstein-Barr, um (4\%) artigo sobre o vírus linfotrópico T humano tipo 1 e um (4\%) artigo sobre a Simkania negevensis.

O enfoque profilático como medida terapêutica estava presente em dez (40\%) dos 25 artigos avaliados. Apenas dois (8\%) dos 25 artigos não avaliaram medidas terapêuticas, apresentando como enfoque dos seus estudos a análise ampla dos quadros infeciosos associados aos receptores do transplante renal. Sendo que um dos artigos avaliou a prevalência de bacteriúria assintomática dois meses pós-transplante e o outro avaliou as infecções pós-transplante e o possível impacto da idade na incidência dessas infecções.

\section{DISCUSSÃO}

Indubitavelmente, os benefícios do transplante renal são imensuráveis para a qualidade de vida do paciente receptor. Contudo, as complicações infeciosas representam uma importante causa de morbimortalidade desse procedimento. Dados apontam que as infecções pós-transplante estejam relacionadas com aproximadamente $14 \%$ dos óbitos em pacientes com DRC. Isto posto, fundamenta-se a importância de se compreender os padrões de infecções para que medidas terapêuticas possam ser implementadas (STARCK É, et al., 2020).

As infecções pós-transplante renal apresentam certo padrão. No primeiro mês normalmente ocorrem infecções bacterianas, fúngicas e virais; principalmente bacterianas associadas ao ambiente hospitalar (Nocardia, Listeria monocytogenes, Mycobacterium tuberculosis, Clostridium difficile). Do primeiro ao sexto mês normalmente ocorrem infecções virais, sendo causada por patógenos tais quais: citomegalovírus, epstein-barr, vírus da hepatite B e C, dentre outros. A partir do sexto mês normalmente ocorrem inf ecções do sistema respiratório por meio dos agentes: Staphylococcus hemolyticcus, Pneumonicytis carinni e Aspergillus (TIZO JM e MACEDO LC, 2015).

Estudos sorológicos recentes mostram a prevalência de uma nova bactéria nos pacientes receptores de transplante renal (RTR) e hemodiálise chamada de Simkania negevensis. Contudo, ainda são desconhecidas as possíveis complicações renais que essa inf ecção possa causas nos RTR (ANGELETTI A, et al., 2017).

Em um estudo realizado com 87 pacientes sobre as complicações infecciosas no primeiro ano pós transplante renal, obteve-se uma incidência de $56,3 \%$ de quadros infeciosos. Os sítios de infecção foram: trato urinário inferior $(48,4 \%)$, trato urinário superior $(11,6 \%)$, vias aéreas superiores $(9,5 \%)$, trato gastrointestinal $(6,3 \%)$, tecidos moles $(4,2 \%)$ e outros sítios $(20 \%)$. Os principais agentes infecciosos foram: E.coli $(10,6 \%)$, Citomegalovírus $(9,5 \%)$, Candida albicans $(4,2 \%)$, Enterobacter sp. $(4,2 \%)$, Staphylococcus sp. $(3,1 \%)$. Contudo, vale pontuar que $56,8 \%$ dos episódios infecciosos não tiveram o agente etiológico determinado (STARCK É, et al., 2020).

O presente trabalho prosseguiu mediante a análise de 25 artigos, os quais foi avaliado os tipos de infecções associados a pacientes RTR e as medidas terapêuticas relacionadas a esses quadros infecciosos. 
Subsequentemente será feito o desenvolvimento desses tópicos. As complicações infecciosas associadas a pacientes RTR possuem um grande impacto em sua morbimortalidade e taxa de sucesso. (HEMMERSBACH MILLER M, et al., 2019).

Comparando-se as infecções após o transplante renal entre paciente jovens e idosos foi observado que as Infecções do Trato Urinário (ITU) e a viremia por Citomegalovírus (CMV) são mais comuns entre idosos. A incidência aumentada de infecções nesse grupo pode ser atribuída a imunossenescência e as múltiplas comorbidades, sendo necessária a adequação dos esquemas imunossupressores e profiláticos (HEMMERSBACH-MILLER M, et al., 2019).

Visando a redução da disfunção óssea provocada pelo uso da terapia imunossupressora utilizada pelos RTR, o uso do anticorpo monoclonal humano contra o receptor ativador do ligante do fator nuclear $\mathrm{Kb}$ (RANKL), Denosumab, tem apresentado bons resultados. Contudo, essa medicação aumenta a incidência de infecções do trato urinário (BONANI M, et al., 2017).

Atualmente visando aumentar o número de possíveis doadores em alguns casos específicos é aceita a realização do transplante renal com incompatibilidade do grupo sanguíneo entre o receptor e doador. Mediante a isso, os protocolos de imunossupressão são potencializados utilizados doses mais altas de Rituximab e imunoglobulina intravenosa. Esse esquema porem aumento os riscos de complicações inf ecções do paciente. Em um estudo publicado em 2020 demonstra que a utilização de uma dose baixa de Rituximab (100mg) é capaz de promover a imunossupressão necessária e ainda diminui a incidência de complicações infeciosas quando comparado com a utilização de doses mais altas (200mg) (THUKRAL S, et al., 2021).

A bacteriúria assintomática ocorre quando o paciente apresenta bactérias em amostras de urina sem possuir nenhum tipo de sintoma. Segundo dados de uma pesquisa europeia mais de $90 \%$ dos médicos realizam o rastreamento para bacteriúria assintomática em seus pacientes com transplante renal. Sendo que em alguns casos de bacteriúria assintomática é feita antibioticoterapia. Todo esse manejo realizado objetiva um bom prognóstico e diminuição do risco do risco de evolução para ITU sintomática e pielonefrite dos pacientes pós transplante renal. Contudo, no estudo realizado por Coussement J, et al (2019) essa ideia é refutada (COUSSEMENT J, et al., 2019).

O estudo demonstrou uma prevalência de $3,4 \%$ de bacteriúria assintomática em RTR e menos de 10\% dos pacientes não tratados com bacteriúria assintomática progrediram para pielonefrite. Outro estudo realizado por Coussement $\mathrm{J}$, et al. (2021) foi avaliado a eficácia da implementação de antibioticoterapia para pacientes pós transplante renal com bacteriúria assintomática com intuito de prevenir a evolução para ITU sintomática. As incidências de ITU sintomática dos grupos foram muito próximas, com incidência de $27 \%$ no grupo dos pacientes com antibioticoterapia e 31\% no sem antibioticoterapia. Dessa forma, novos estudos devem ser feitos para aprimoramento dos procedimentos de rastreamento e definição de protocolos adequados para a prescrição de antibióticos (COUSSEMENT J, et al., 2019 e 2021).

A ITU sintomáticaé a complicação infeciosa mais comum em pacientes com transplante renal, dessa forma é de fundamental importância que sejam adotadas medidas profiláticas e terapêuticas para mitigar essa complicação. Dentre as medidas profiláticas que podem ser adotadas vale ressaltar: a utilização da Fosfomicina e o correto manejo dos stents uretéricos. A fosfomicina é um antibiótico que apresenta espectro para grande parte de enterobactérias presentes na urina sendo utilizada como agente profilático em vários procedimentos urológicos. Em um estudo publicado em 2020, aponta que a associação de fosfomicina intravenoso com trimetropim/sulfametoxazol foi capaz de reduzir a incidência de ITU sintomática (ROSADO CANTO R, et al., 2020).

O uso de stent ureteral profilático em RTR reduz a incidência de determinadas complicações urológicas, contudo, está associado as suas próprias complicações como a ocorrência de ITU sintomática. Em estudo realizado no Reino Unido demonstrou que a retirada do stent ureteral no quinto dia pós transplante renal reduziu a incidência de complicações infecciosas atreladas ao seu uso. Sendo as taxas de incidência de complicações infecciosas de $28,6 \%$ no grupo onde a remoção do stent foi tardia e de $7,6 \%$ no grupo com remoção do stent precoce (PATEL P, et al., 2017). 
Com relação ao tratamento da ITU sintomática em pacientes RTR o tratamento com finafloxacino (800mg) porcinco dias ou dez dias se mostrou eficaz para a resolução de ITU complicada ou pielonef rite, apresentando melhores resultados quando comparado ao uso de dez dias de ciprofloxacina. Vale ressaltar que a antibioticoterapia eficaz com um período de tratamento menor apresenta benefícios como: redução das chances de desenvolvimento de resistência ao medicamento, redução do tempo de internação e redução de complicações (WAGENLEHNER F, et al., 2018).

A infecção pelo Citomegalovírus (CMV) é a infecção oportunística mais comum em pacientes pós transplante renal, podendo ser causada por reativação endógena ou contaminação exógena. O CMV pode gerar quadros assintomáticos, de síndrome viral e doença invasiva tecidual. As reverberações imunológicas geradas pelo CMV aumentam o risco de rejeição aguda e de infecções (BASIC-JUKIC N, et al., 2019). Estudos recentes apontam que as células $T$ secretoras de IFN-gama de memória/efetor específico IE-1 para citomegalovírus estão relacionadas com mecanismos de reatividade cruzada resultando em rejeição do enxerto e pior função (STRANAVOVA L, et al., 2019).

Haja vista os desfechos desfavoráveis associados com a infecção pelo CMV em pacientes RTR é fundamental a implementação de estratégias profiláticas. A profilaxia com medicamentos antivirais é padrão de cuidado, sendo o Valganciclovir o medicamento mais comumente utilizado devido a sua eficácia e segurança (BASIC-JUKIC N, et al., 2019). Estudos apontam que a profilaxia com Valganciclovir em dose baixa $(450 \mathrm{mg})$ para pacientes com risco intermediário é eficaz e mais custo -ef etivo comparado com a dose padrão (900mg) (GHEITH O, et al., 2017; HALIM MA, et al., 2019).

Em uma análise das formulações genéricas do Valganciclovir verificou-se a eficácia e segurança desses medicamentos, contudo novos estudos devem ser feitos para corroborar tal ac hado. Por fim, a profilaxia para CMV com Valganciclovir apresenta menor risco de fibrose intersticial moderada a grave e atrofia tubular quando comparada a com Valaciclovir (BASIC-JUKIC N, et al., 2019; REISCHIG T, et al., 2018).

Uma nova opção profilática para a infecção do CMV em pacientes RTR é o RG7667, medicação oriunda da combinação de dois anticorpos monoclonais lgG1 anticitomegalovírus. Tal medicação tem como mecanismo de ação o bloqueio da entrada das partículas virais do CMV dentro das células. Em RTR de alto risco a medicação diminuiu a incidência da infecção entre 12 e 24 semanas após o transplante e atrasou o tempo de viremia. Por fim, estudos devem ser feitos para definições posológicas e indicações de uso (DENG R, et al, 2018; ISHIDA JH, et al.,2017).

O Poliomavírus BK (BKV) é bastante prevalente e comumente não gera reverberações clínicas aos portadores imunocompetentes. Contudo, em pacientes RTR devido a terapia imunossupressora, os mesmos se tornam vulneráveis a ativação das partículas virais. A infecção pelo BKV em RTR está associada com nefropatia do enxerto em 10\% dos pacientes, com perda subsequente do enxerto de até 70\% (PATEL SJ, et al., 2019).

Não existe esquema profilático eficaz comprovado para o BKV. As fluorquinolonas demonstraram atividade in vitro contra o BKV, mediante a isso foi testada a eficácia in vivo de um esquema profilático utilizando a Ciprofloxacina, contudo o mesmo foi ineficaz e aumentou o risco de infecções resistentes as fluorquinolonas (PATEL SJ, et al., 2019).

A coinfecção de BKV e CMV em pacientes RTR está associada com rejeição aguda e função inferior do enxerto. A monitorização da carga viral e a realização de biópsia renal são procedimentos que podem ser realizados para avaliar o status clínico do paciente e possíveis riscos de danos ao enxerto (JEHN U, et al., 2020; BLAZQUEZ-NAVARRO A, et al., 2018).

A infecção pelo Vírus da Hepatite A (HAV) também apresenta relevância no contexto de pacientes RTR, haja vista que em indivíduos imunodeprimidos e com idade mais avançada os riscos de apresentações clínicas mais graves são mais altos. Desta forma, indivíduos que desenvolveram formas de insuficiência hepática fulminante possuem um risco maior de evolução para lesão renal aguda e perda do enxerto. Haja vista a ausência de terapia antiviral especifica para essa infecção, as estratégias profiláticas são fundamentais. A vacinação para HAV é feita com esquemas de duas doses, sendo fundamental para a 
prevenção da doença. Por fim, estudos utilizando esquemas vacinais de três doses não demonstraram aumento da imunogenicidade, sendo que outros esquemas para receptores de transplantes devem ser pesquisados (PRASOPPOKAKORN T, et al., 2021).

A infecção pelo Vírus da Hepatite C (HCV) ao longo de sua história natural pode causar em pacientes portadores da infecção crônica a doença renal e hepática em estágio terminal, sendo necessário em alguns casos a realização de transplante desses órgãos. Desta forma, é fundamental que em pacientes RTR sejam eliminadas as partículas virais para diminuir os riscos de complicações associadas com a infecção pelo HCV. O tratamento da infecção por HCV atualmente é feito utilizando fármacos chamados de Antivirais de Ação Direta (DAA), os quais são combinados em diferentes esquemas terapêuticos (REAU N, et al., 2018).

Uma opção segura e eficaz para o tratamento do HCV em RTR sem o uso Ribavirina é o uso uma vez ao dia por 12 semanas de Glecaprevir/pibrentasvir. Por fim, vale pontuar que o uso de DAA em RTR infectado pelo HCV mostrou-se eficaz a longo prazo. (REAU N, et al., 2018; ZHANG J, et al., 2019).

A infecção pelo Vírus Epstein-Barr (EBV) em pacientes RTR pode resultar em uma complicação maligna e potencialmente fatal chamada de Doença Linfoproliferativa Pós-Transplante (DLPT), a qual está associado a alterações da homeostase das células $B$. Foi observado que com a reativação da inf ecção houve aumento dos níveis de BAFF (BAJDA S, et al., 2020).

A infecção pelo Vírus linfotrópico T humana tipo 1 (HTLV-1) é rara em pacientes RTR e está associada com linfoma-leucemia de células T adultas (ATL), distúrbio linfoproliferativo pós-transplante (PTLD) e mielopatia associada ao HTLV-1 (HAM) ou HAM atípica (KAWANO N, et al., 2018).

Por fim, tendo em vista o atual contexto epidemiológico associado com a pandemia do SARS-CoV-2 é fundamental compreender as implicações geradas por sua infecção em pacientes RTR. Sendo necessário que o manejo da terapia imunossupressora seja individualizado e acordada com o centro de transplante responsável pelo paciente (MERINO JC de la F, et al., 2020).

\section{CONSIDERAÇÕES FINAIS}

As complicações infecciosas são uma importante causa de morbimortalidade em pacientes receptores de transplante renal. Dessa forma, foi observado que como reflexo da terapia imunossupressora e outros fatores, tais receptores estão vulneráveis a desenvolverem variados quadros infecciosos, possuindo diferentes agentes etiológicos, desfechos e medidas terapêuticas. Sendo as Infecções do Trato Urinário a complicação infecciosa mais comum. Portanto, é de fundamental importância a capacitação das equipes responsáveis por pacientes receptores de transplante renal, para que adotem medidas assertivas e baseadas em evidencias cientificas no intuito de prevenirem e tratarem de forma adequada os quadros infeciosos.

\section{REFERÊNCIAS}

1. ANGELETTI A, et al. Seroprevalence of a "new" bacterium, Simkania negevensis, in renal transplant recipients and in hemodialysis patients. BMC Nephrol, 2017; 18: 133.

2. BAJDA S, et al. The role of soluble mediators in the clinical course of EBV infection and B cell homeostasis after kidney transplantation. Sci Rep, 2020; 10: 19594.

3. BARBOSA JT, et al. Transplante renal: mecanismo de rejeição, terapia imunossupressora e métodos diagnósticos. Saúde e Desenvolvimento, 2020;9(17).

4. BASIC-JUKIC N, et al. A Comparison of Different Valgancyclovir Formulations in the Universal 6-Month Prophylaxis Against CMV Infection in Renal Transplant Recipients: A Randomized Single-Centre Study. PRILOZI, 2019;40(3):4755.

5. BLAZQUEZ-NAVARRO A, et al. BKV, CMV, and EBV Interactions and their Effect on Graft Function One Year PostRenal Transplantation: Results from a Large Multi-Centre Study. EBioMedicine, 2018;34:113-21.

6. BONANI M, et al. Infections in De Novo Kidney Transplant Recipients Treated With the RANKL Inhibitor Denosumab. Transplantation, 2017; 101:2139-45.

7. COUSSEMENT J, et al. Antibiotics versus no therapy in kidney transplant recipients with asymptomatic bacteriuria (BiRT): a pragmatic, multicentre, randomized, controlled trial. Clinical Microbiology and Infection, 2021; 27(3): 398405 . 
8. COUSSEMENT J, et al. Prevalence of asymptomatic bacteriuria among kidney transplant recipients beyond two months post-transplant: A multicenter, prospective, cross-sectional study. PLoS ONE, 2019; 14: e0221820.

9. DENG R, et al. Pharmacokinetics and Exposure-Response Analysis of RG7667, a Combination of Two Anticytomegalovirus Monoclonal Antibodies, in a Phase 2a Randomized Trial To Prevent Cytomegalovirus Infection in High-Risk Kidney Transplant Recipients. Antimicrob Agents Chemother, 2018;62.

10. GARCIA GG, et al. The global role of kidney transplantation. Braz J Nephrol, 2012;34: 01-07.

11. GHEITH O, et al. Successful Cost-Effective Prevention of Cytomegalovirus Disease in Kidney Transplant Recipients Using Low-Dose Valganciclovir. Exp Clin Transplant, 2017; 15: 156-63.

12. HALIM MA, et al. Extended Efficacy of Low-Dose Valganciclovir for Prevention of Cytomegalovirus Disease in Intermediate-Risk Kidney Transplant Recipients: Two-Year Follow-Up. Exp Clin Transplant, 2019; 17: 339-43.

13. HEMMERSBACH-MILLER M, et al. Infections after kidney transplantation. Does age matter?. Clin Transplant, 2019; 33: e13516.

14. ISHIDA JH, et al. Phase 2 Randomized, Double-Blind, Placebo-Controlled Trial of RG7667, a Combination Monoclonal Antibody, for Prevention of Cytomegalovirus Infection in High-Risk Kidney Transplant Recipients. Antimicrob Agents Chemother, 2017;61.

15. JEHN U, et al. Clinical features of BK-polyomavirus and cytomegalovirus co-infection after kidney transplantation. Sci Rep, 2020;10(1): 22406.

16. KAWANO N, et al. The clinical impact of human T-lymphotrophic virus type 1 (HTLV-1) infection on the development of adult T-cell leukemia-lymphoma (ATL) or HTLV-1-associated myelopathy (HAM) / atypical HAM after allogeneic hematopoietic stem cell transplantation (allo-HSCT) and renal transplantation. JCEH, 2018; 58: 107-21.

17. MERINO JCF, et al. Manejo de un paciente con trasplante renal en terapia de mantenimiento con COVID -19 en un hospital no trasplantador. Rev colomb nefrol, 2020;123-131.

18. PATEL P, et al. Prophylactic Ureteric Stents in Renal Transplant Recipients: A Multicenter Randomized Controlled Trial of Early Versus Late Removal. Am J Transplant, 2017; 17:2129-38.

19. PATEL SJ, et al. Ciprofloxacin for BK viremia prophylaxis in kidney transplant recipients: Results of a prospective, double-blind, randomized, placebo-controlled trial. Am J Transplant, 2019;19: 1831-1838.

20. PIOVESAN A e NAHAS WC. Estado atual do transplante renal no Brasil e sua inserção no contexto mundial. Rev. Med., 2018; 97(3):334-343.

21. PRASOPPOKAKORN T, et al. A randomized controlled trial of comparative effectiveness between the 2 dose and 3 dose regimens of hepatitis a vaccine in kidney transplant recipients. Sci Rep, 2021;11: 50.

22. REAU N, et al. Glecaprevir/Pibrentasvir Treatment in Liver or Kidney Transplant Patients With Hepatitis C Virus Infection. Hepatology, 2018;68: 1298-1605.

23. REISCHIG T, et al. Less renal allograft fibrosis with valganciclovir prophylaxis for cytomegalovirus compared to high dose valacyclovir: a parallel group, open-label, randomized controlled trial. BMC Infect Dis, 2018; 18: 573.

24. ROSADO-CANTO $\mathrm{R}$, et al. Perioperative fosfomycin disodium prophylaxis against urinary tract infection in renal transplant recipients: a randomized clinical trial. Nephrol Dial Transplant, 2020;35: 1996-2003.

25. STARCK É, et al. Complicações infecciosas no primeiro ano pós-transplante renal. BJD, 2020;6(6): 36663-36676.

26. STRANAVOVA L, et al. Heterologous Cytomegalovirus and Allo-Reactivity by Shared T Cell Receptor Repertoire in Kidney Transplantation. Front Immunol, 2019;10:2549.

27. THUKRAL S, et al. Effect of Different Rituximab Doses on B Cell Count, Anti-A/B Antibody Titer, Graft Function, and Infectious Complications in ABO-Incompatible Renal Transplantation: A Prospective Study. Transplantation Proceedings, 2021;53: 970-975.

28. TIZO JM e MACEDO LC. Principais Complicações E Efeitos Colaterais Pós-Transplante Renal. Uningá Review Journal, 2015;24: 1 .

29. WAGENLEHNER F, et al. Explorative Randomized Phase II Clinical Study of the Efficacy and Safety of Finafloxacin versus Ciprofloxacin for Treatment of Complicated Urinary Tract Infections. Antimicrob Agents Chemother, 2018;62(4).

30. ZHANG J, et al. Long-term follow-up of HCV infected kidney transplant recipients receiving direct-acting antiviral agents: a single-center experience in China. BMC Infect Dis, 2019; $19: 645$. 